\title{
High-frequency oscillatory ventilation is an effective treatment for severe pediatric acute respiratory distress syndrome with refractory hypoxemia
}

This article was published in the following Dove Press journal:

Therapeutics and Clinical Risk Management

19 October 2016

Number of times this article has been viewed

\author{
Yu-Xiong Guol,* \\ Zhao-Ni Wang ${ }^{2, *}$ \\ Ya-Ting Li ${ }^{2}$ \\ Li Pan ${ }^{2}$ \\ Li-Fen Yang ${ }^{2}$ \\ Yan $\mathrm{Hu}^{\prime}$ \\ Yue-Yu Sun' \\ Liang-Ming $\mathrm{Cai}^{2}$ \\ Zhuang-Gui Chen² \\ 'Pediatric Intensive Care Unit, \\ Department of Pediatrics, \\ Guangdong General Hospital, \\ Guangdong Academy of Medical \\ Sciences, ${ }^{2}$ Pediatric Intensive Care \\ Unit, Department of Pediatrics, \\ The Third Affiliated Hospital of \\ Sun Yat-sen University, Guangzhou, \\ People's Republic of China \\ *These authors contributed equally \\ to this work
}

Background and purpose: Early or primary application of high-frequency oscillatory ventilation (HFOV) has been recently suggested not to offer benefit to patients with acute respiratory distress syndrome (ARDS). However, the rescue effects of HFOV on severe pediatric acute respiratory distress syndrome (PARDS) with hypoxemia refractory to conventional mechanical ventilation (CMV) remain unclear. This study aimed to determine whether severe PARDS children would benefit from HFOV when oxygenation deteriorated on CMV and to identify any potential risk factors related to mortality.

Patients and methods: In a retrospective and observational study, 48 children with severe PARDS between January 2009 and July 2015 were divided into two groups: 26 in HFOV group and 22 in CMV group. Data regarding demographic, underlying conditions, arterial blood gases and clinical outcomes were collected and analyzed.

Results: The arterial partial pressure of oxygen $\left(\mathrm{PaO}_{2}\right)$ /fraction of inspiration oxygen $\left(\mathrm{FiO}_{2}\right)$ ratio and $\mathrm{PaO}_{2}$ improved significantly during $\mathrm{HFOV}$, whereas arterial partial pressure of carbon dioxide $\left(\mathrm{PaCO}_{2}\right)$ and oxygenation index decreased. There was no statistical difference in the in-hospital mortality between the groups $(P=0.367)$. The odds ratio of survival in HFOV group was 2.74 ( $95 \%$ confidence interval 0.52 to $14.58, P=0.237)$. The pediatric intensive care unit length of stay and total ventilation duration were longer in HFOV group ( $P=0.048$ and $P=0.000$, respectively). Vasoactive agents were used more frequently in HFOV group $(P=0.007)$. The incidence of new air leak was similar between the two groups $(P=0.674)$. The presence of multiple organ dysfunction syndrome and heavier body weight were identified as predictors of mortality in the HFOV group ( $P=0.006$ and $P=0.020$, respectively).

Conclusion: HFOV as an efficient alternative therapy could significantly improve hypoxemia and promote $\mathrm{CO}_{2}$ removal in severe PARDS children when oxygenation progressively worsens on CMV.

Keywords: pediatric acute respiratory distress syndrome, high-frequency oscillatory ventilation, mechanical ventilation, children

\section{Introduction}

Acute respiratory distress syndrome (ARDS) is one of the critical diseases in pediatric intensive care units (PICUs) and is associated with high mortality. A recent report indicated that the mortality due to ARDS had significantly reduced over the past two decades but continued to be high at $\sim 20 \%-40 \%{ }^{1}$ and was even higher in severe patients, classified based on the severity stratification of the Berlin definition. ${ }^{2}$ Respiratory failure, presented as hypoxemia with or without hypercapnia, is the predominant characteristic of ARDS and the common cause of death. Mechanical ventilation is
Correspondence: Zhuang-Gui Chen Pediatric Intensive Care Unit, Department of Pediatrics, The Third Affiliated Hospital of Sun Yat-sen University, 600 Tianhe Road, Guangzhou 510630, People's Republic of China Tel +860208525 3380 Email chenzhuanggui@126.com (c) (1) (5) 2016 Guo et al. This work is published and licensed by Dove Medical Press Limited. The full terms of this license are available at https://www.dovepress.com/terms.php

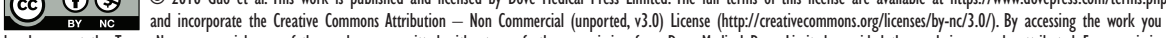
hereby accept the Terms. Non-commercial uses of the work are permitted without any further permission from Dove Medical Press Limited, provided the work is properly attributed. For permission for commercial use of this work, please see paragraphs 4.2 and 5 of our Terms (https://www.dovepress.com/terms.php). 
the lifesaving treatment for ARDS. However, conventional mechanical ventilation (CMV), especially the compulsory pattern, may generate secondary lung injuries such as volutrauma and barotrauma and might involve additional mortality risks. ${ }^{3}$ Nowadays, more and more critical care practitioners implement a lung-protective strategy using small tidal volumes and restrictive pressure. However, we cannot ignore the fact that a large population, especially those with severe hypoxemia, is refractory to conventional lung-protective ventilation strategies, which necessitates the exploration of alternative approaches for these patients.

High-frequency oscillatory ventilation (HFOV), considered as a lung-protective ventilatory mode, ${ }^{4}$ is utilized with low tidal volumes and high flow rates, which theoretically contribute to averting volutrauma such as excessive alveolar distension and high peak airway pressures, to facilitate lung recruitment. On the other hand, the persistent airway pressure delivered by HFOV prevents lung collapse. ${ }^{5,6}$ Some studies have demonstrated that HFOV could improve hypercapnia and oxygenation in children with ARDS and may be safely used. ${ }^{7,8}$ Recently, the Pediatric Acute Lung Injury Consensus Conference recommends the use of HFOV in pediatric patients with severe ARDS as a rescue therapy when conventional ventilation fails. ${ }^{9}$ On the contrary, a recent randomized trial in adults concluded that HFOV had no significant effect on mortality or economic advantage in patients with ARDS. ${ }^{10}$ Another retrospective observational study also failed to prove the positive efficacy of HFOV on the outcomes of pediatric patients. ${ }^{11}$ Given the controversial role of HFOV as a therapy approach and the unclear effect on the outcomes of ARDS in children, the present study aims to estimate whether PARDS patients with refractory hypoxemia who deteriorated on CMV could benefit from HFOV and to identify risk factors contributing to the mortality of PARDS patients.

\section{Patients and methods}

\section{Study design}

This observational retrospective study was carried out in the PICUs of Guangdong General Hospital and the Third Affiliated Hospital of Sun Yat-sen University from January 2009 to July 2015. Patients aged from 28 days to 14 years with proven diagnosis of ARDS as well as meeting the severe degree were included in the study. The diagnosis and degree of severity were defined according to the most recent recommended criteria from the Pediatric Acute Lung Injury Consensus Conference held in 2015. ${ }^{9}$ In terms of the criteria, PARDS patients with oxygenation index $(\mathrm{OI}) \geq 16 \mathrm{cmH}_{2} \mathrm{O} / \mathrm{mmHg}$ were defined as severe-degree patients. However, pediatric patients requiring intubation and mechanical ventilation due to fatal head injury, patients who received mechanical ventilation for less than 24 hours or those who withdrew treatment were excluded. Using the hospital databases, all patients with accessible records were identified and divided into two study groups: patients undergoing HFOV for more than 24 hours with a HFOV device (model 3100A; CareFusion, Yorba Linda, CA, USA) were enrolled in the HFOV group and patients who received the usual ventilatory care with the devices available in the PICUs (Evita IV or XL; Drager, Lubeck, Germany) or receiving HFOV for less than 24 hours were enrolled in the CMV group (Figure 1). Three patients received $\mathrm{HFOV}$ more than once; therefore, data for each patient were collected from the first run of HFOV. A total of 48 pediatric patients, 26 in the HFOV group and 22 in the CMV group, were analyzed with respect to the demographic data, ventilation setting, arterial blood gas and clinical outcomes. All clinical data were obtained from electronic medical records and collated using Excel software (Microsoft Office Professional Plus 2007). This study gained the approval from the ethics committees of Guangdong General Hospital and the Third Affiliated Hospital of Sun Yat-sen University.

The data regarding the baseline characteristics of the patients, including age, sex, admission weight, coexisting medical conditions and Pediatric Risk of Mortality III (PRISM III) score, were collected. Data regarding the ventilatory settings, including the levels of positive end expiratory pressure (PEEP), peak inspiratory pressure (PIP), mean airway pressure (MAP), respiratory rate and fraction of inspiration oxygen $\left(\mathrm{FiO}_{2}\right)$, at the initiation of $\mathrm{CMV}$ and immediately preceding HFOV were also collected. The primary outcomes included the oxygenation parameters and in-hospital mortality. Information regarding changes in arterial partial pressure of oxygen $\left(\mathrm{PaO}_{2}\right), \mathrm{PaO}_{2} / \mathrm{FiO}_{2}$ ratio, OI $\left(\mathrm{OI}=\mathrm{MAP} \times \mathrm{FiO}_{2} \times 100 / \mathrm{PaO}_{2}\right)$, potential of hydrogen $(\mathrm{pH})$ and partial pressure of carbon dioxide $\left(\mathrm{PaCO}_{2}\right)$ during $\mathrm{HFOV}$ were collected and calculated immediately preceding HFOV or at the initiation of CMV, at end of the first three days and on the last day after commencing HFOV. The secondary outcomes in the study included the use of vasoactive agents, length of PICU stay, mechanical ventilation duration and occurrence of new air leaks during HFOV and CMV.

\section{Ventilation strategy}

All children were primarily started on CMV. We applied a lung-protective ventilation strategy with small tidal volumes (5-8 $\mathrm{mL} / \mathrm{kg}$ predicted body weight) and controlled 


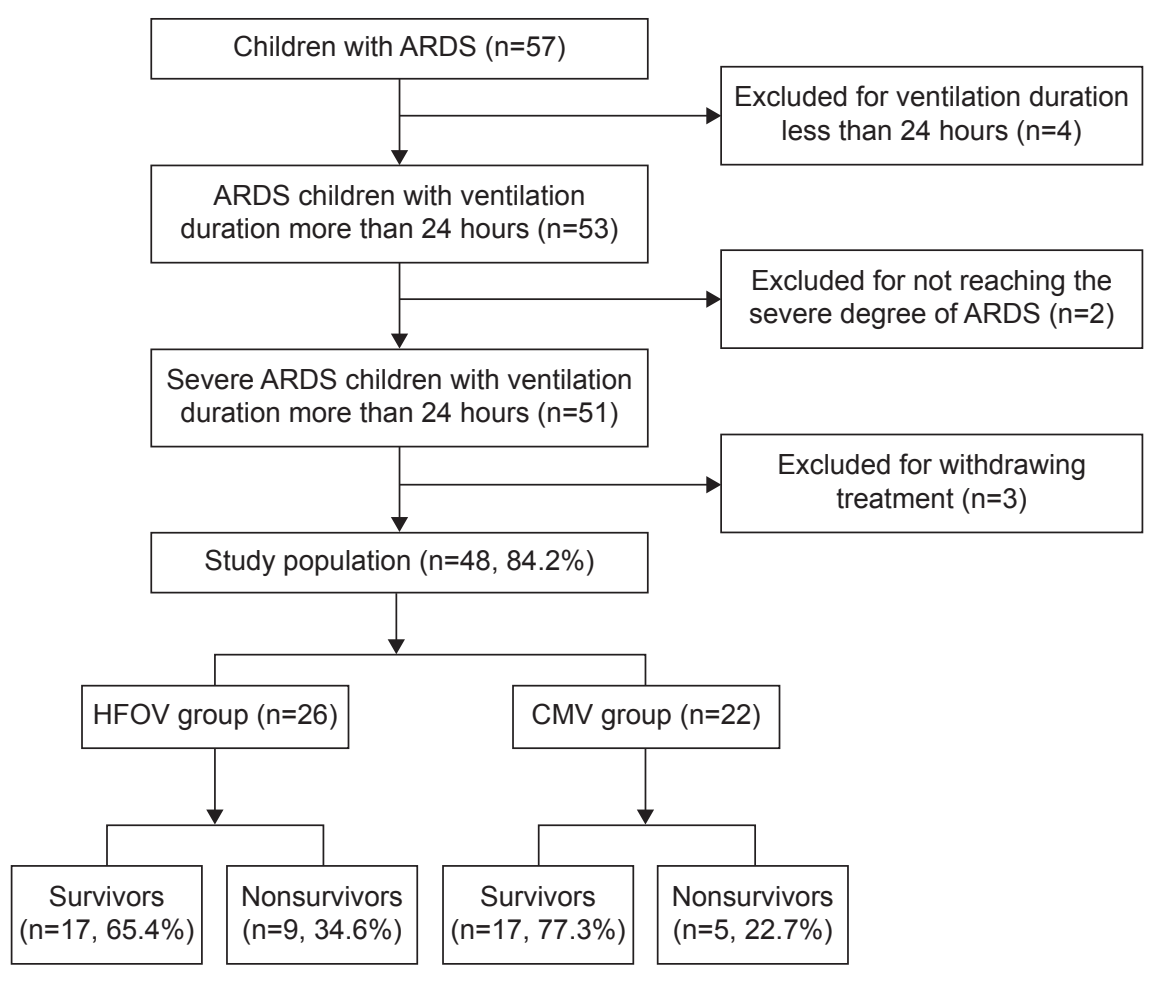

Figure I Flow diagram for children with acute respiratory distress syndrome.

Abbreviations: ARDS, acute respiratory distress syndrome; HFOV, high-frequency oscillatory ventilation; CMV, conventional mechanical ventilation.

pressures (inspiratory plateau pressures lower than $30 \mathrm{cmH}_{2} \mathrm{O}$, allowing slightly higher inspiratory plateau pressure for $30-35 \mathrm{cmH}_{2} \mathrm{O}$ ). ${ }^{12,13}$ Patients were converted to HFOV when one or more of the following conditions existed: 1 ) refractory hypoxemia with OI more than $30 \mathrm{cmH}_{2} \mathrm{O} / \mathrm{mmHg}$, which was considered failure of conventional care in our practice and was also described by Esan et al; ${ }^{14}$ 2) plateau pressure surpassing $30 \mathrm{cmH}_{2} \mathrm{O}$ for at least two hours even when applying permissive hypercapnia. The $\mathrm{FiO}_{2}$ was usually set as $100 \%$ at the beginning of HFOV. MAP was initially set $2-3 \mathrm{cmH}_{2} \mathrm{O}$ above the last MAP on CMV and then increased to maintain the arterial saturation larger than $90 \%$ and $\mathrm{PaO}_{2}$ above $60 \mathrm{mmHg}$. mPaw and $\mathrm{FiO}_{2}$ could be further optimized based on oxygenation when there is no indication of lung overinflation or hemodynamic instability. The amplitude of oscillation should maintain the vibration of chest wall to the pelvis. Frequency was set according to the weights and the conditions of lung compliance. A frequency of $12-15 \mathrm{~Hz}$ was applied for the children weighing $<10 \mathrm{~kg}$ and $5-8 \mathrm{~Hz}$ was used for those weighing $>10 \mathrm{~kg}$. The amplitude of oscillation and frequency were adjusted to reach a permissive hypercapnia with $\mathrm{PaCO}_{2}$ of 50-60 mmHg and $\mathrm{pH} \geq 7.25$. HFOV failure was defined as persistent hypoxemia $\left(\mathrm{FiO}_{2}\right.$ decreased less than $10 \%$ within 24 hours) or refractory hypercapnia $\left(\mathrm{PaCO}_{2}>120 \mathrm{mmHg}\right.$, $\mathrm{pH}<7.15$ ). Patients were considered to convert back to CMV when the HFOV setting of $\mathrm{FiO}_{2}<50 \%$, mPaw $10-20 \mathrm{cmH}_{2} \mathrm{O}$ and amplitude of oscillation $<30 \mathrm{cmH}_{2} \mathrm{O}$ can achieve well oxygenation $\left(\mathrm{SpO}_{2}>90 \%, \mathrm{PaO}_{2}>60 \mathrm{mmHg}\right)$.

\section{Statistical analysis}

Continuous data, such as weight, were presented as mean and standard deviation (SD) if normally distributed or median and interquartile range if not distributed normally. Categorical data, such as sex, were presented using frequencies and percentages. Continuous variables were compared using the independent-samples $t$-test or the Mann-Whitney $U$-test. Categorical variables were compared using the Fisher's exact or Pearson's chi-square test. The association between ventilation mode and mortality was further determined by adjusting for confounders using a multivariate logistic regression. Kaplan-Meier survival curves for two ventilation groups were compared using a log-rank test. The development of parameters over time including OI, $\mathrm{PaO}_{2} / \mathrm{FiO}_{2}$ ratio, $\mathrm{PaO}_{2}$, $\mathrm{PaCO}_{2}$ and $\mathrm{pH}$ of HFOV group was analyzed using generalized estimating equations. Risk factors potentially affecting the mortality in each ventilation group were identified using a Cox proportional hazard model. Differences were considered statistically significant when two-tailed $P$-values were less than 0.05. Calculations were performed using SPSS Statistics, version 20.0 (IBM, Armonk, NY, USA). 


\section{Results}

\section{Patient characteristics}

All patients met the 2015 recommended diagnostic criteria for pediatric ARDS and reached a severe degree of severity. The median (interquartile range) age of the study population was 20.00 (43.75) months, with a median (interquartile range) weight of $10.00(9.98) \mathrm{kg}$. There were 26 males (54.17\%) in the study cohort, and the median (interquartile range) PRISM III score was 8.00 (7.50).

\section{Characteristics related to mode of mechanical ventilation}

Table 1 presents the baseline characteristics and the outcomes of patients grouped by ventilation mode. Children in the HFOV group were younger compared to those in the CMV group (9.00 median [21.75 IQR] vs 40.50 median [48.75 IQR] months, $P=0.002$ ) and presented with a lower admission weight (6.55 [5.83] vs $14.75[12.63] \mathrm{kg}, P=0.001)$. The majority of selected ARDS patients presented with more than one coexisting condition. The three most frequent comorbidities in the HFOV group were pneumonia (88.46\%), congenital heart disease $(38.46 \%)$ and immunocompromised state $(26.92 \%)$, while those in the CMV group were pneumonia $(72.73 \%)$, immunocompromised state $(45.45 \%)$ and sepsis (40.91\%). However, there was no significant difference between the two ventilation groups with regard to

Table I Baseline characteristics and outcomes of the patients

\begin{tabular}{llll}
\hline Clinical characteristics & $\begin{array}{l}\text { HFOV } \\
(\mathbf{n = 2 6 )}\end{array}$ & $\begin{array}{l}\text { CMV } \\
(\mathbf{n}=\mathbf{2 2})\end{array}$ & P-value \\
\hline Age/mo & $9.00(21.75)$ & $40.50(48.75)$ & 0.002 \\
Male/numbers & $13(50.0 \%)$ & $13(59.09 \%)$ & 0.573 \\
Weight/kg & $6.55(5.83)$ & $14.75(12.63)$ & $0.00 I$ \\
PRISM III score & $8.77(6.04)$ & $6.59(3.78)$ & 0.150 \\
Diagnosis & & & \\
$\quad$ Pneumonia & $23(88.46 \%)$ & $16(72.73 \%)$ & 0.267 \\
Congenital heart disease & $10(38.46 \%)$ & $3(13.64 \%)$ & 0.053 \\
Immunocompromised & $7(26.92 \%)$ & $10(45.45 \%)$ & 0.232 \\
Sepsis & $5(19.23 \%)$ & $9(40.91 \%)$ & 0.122 \\
CNS disease & $5(19.23 \%)$ & $6(27.27 \%)$ & 0.732 \\
$\quad$ MODS & $4(15.38 \%)$ & $5(22.73 \%)$ & 0.713 \\
Outcomes & & & \\
In-hospital mortality & $9(34.62 \%)$ & $5(22.73 \%)$ & 0.367 \\
Vasoactive agents usage & $25(96.15 \%)$ & $14(63.64 \%)$ & 0.007 \\
New air leak & $4(15.38 \%)$ & $2(9.09 \%)$ & 0.674 \\
PICU LOS/hour & $516.00(600.00)$ & $264.00(246.00)$ & 0.048 \\
Ventilation duration/hour & $444.00(456.00)$ & $144.00(168.00)$ & 0.000 \\
\hline
\end{tabular}

Notes: Data were presented by median (interquartile range) or numbers (percentage). Continued variables were compared using Mann-Whitney U-test and categorical variables using Fisher's exact or Pearson's chi-square test; $P$-value $>0.05$ is considered significant.

Abbreviations: HFOV, high-frequency oscillatory ventilation; CMV, conventional mechanical ventilation; PRISM III score, Pediatric Risk of Mortality III score; CNS, central nervous system; MODS, multiple organ dysfunction syndrome; PICU LOS, pediatric intensive care unit length of stay; mo, months. diagnostic categories. Other baseline characteristics such as sex distribution and PRISM III score were similar between the study groups.

For the outcomes related to the ventilation patterns, patients undergoing HFOV had a longer PICU length of stay (LOS) (516 [600] vs 264 [246] hours, $P=0.048$ ) and duration of mechanical ventilation (444 [456] vs 144 [168] hours, $P=0.000$ ). Additionally, patients undergoing HFOV were exposed to vasoactive agents more frequently than those in the CMV group ( $96.15 \%$ vs $63.64 \%, P=0.007)$. However, the incidence of new air leaks was similar between the two groups (4/26 [15.38\%] vs $2 / 22$ [9.09\%], $P=0.674)$. The in-hospital mortality was not associated with ventilation mode $(P=0.367)$. Even after adjustment for weight, PRISM III score and the presence of congenital heart disease and sepsis, the odds ratio of survival in patients receiving HFOV was 2.74 ( $95 \%$ confidence interval [CI] 0.52 to $14.58, P=0.237$ ) compared to those in the CMV group (Table 2). Figure 2 shows the Kaplan-Meier survival curve for PICU LOS in the two ventilation groups, which indicates that the survival time is not related to the pattern of ventilation $(P=0.769)$.

\section{Blood gas analyses immediately preceding and during HFOV}

Figure 3 shows the change of $\mathrm{OI}, \mathrm{PaO}_{2} / \mathrm{FiO}_{2}$ ratio, $\mathrm{PaO}_{2}$ and $\mathrm{PaCO}_{2}$ during HFOV by comparing the data immediately preceding HFOV. There was a significant increase in the $\mathrm{PaO}_{2} / \mathrm{FiO}_{2}$ ratio on the first day of $\mathrm{HFOV}$ and persisted throughout the remaining study days $(P=0.005,0.008,0.003$ and $<0.001$ for the first 24 hours, 48 hours, 72 hours and the last day, respectively). The $\mathrm{PaO}_{2}$ also showed a remarkable improvement during $\operatorname{HFOV}(P=0.013,0.090,0.008$ and

Table 2 Summary of multivariable logistic regression analysis for mortality

\begin{tabular}{llll}
\hline Variables & $\begin{array}{l}\text { Adjusted } \\
\text { odds ratio for } \\
\text { nonsurvival }\end{array}$ & $\begin{array}{l}\text { 95\% confidence } \\
\text { interval }\end{array}$ & P-value \\
\hline $\begin{array}{l}\text { Ventilation mode } \\
\text { HFOV }\end{array}$ & $\begin{array}{l}2.74^{\mathrm{a}} \\
\mathrm{I}\end{array}$ & $(0.515,14.584)$ & 0.237 \\
$\begin{array}{l}\text { Weight (per every } \\
\text { one unit increase) }\end{array}$ & 1.06 & $(0.969, \mathrm{I} .162)$ & 0.204 \\
$\begin{array}{l}\text { PRISM III score (per } \\
\text { every one unit increase) }\end{array}$ & 1.05 & $(0.922,1.20 \mathrm{I})$ & $0.45 \mathrm{I}$ \\
$\begin{array}{l}\text { Presence of congenital } \\
\text { heart disease }\end{array}$ & 1.3 & $(0.267,6.34 \mathrm{I})$ & 0.745 \\
\begin{tabular}{l} 
Presence of sepsis \\
\hline
\end{tabular} & 1.31 & $(0.279,6.153)$ & $0.73 \mathrm{I}$ \\
\hline
\end{tabular}

Notes: ${ }^{2}$ The odd ratio of mortality in patients receiving HFOV was adjusted by weight, PRISM III score and the presence of congenital heart disease and sepsis; $P$-value $>0.05$ is considered significant.

Abbreviations: HFOV, high-frequency oscillatory ventilation; CMV, conventional mechanical ventilation; PRISM III score, Pediatric Risk of Mortality III score. 


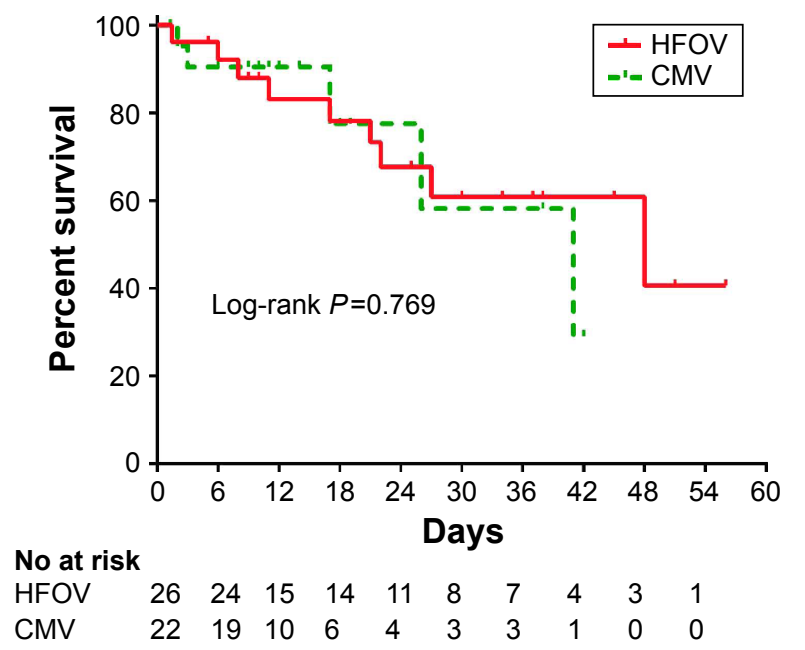

Figure 2 Kaplan-Meier survival curve for pediatric intensive care unit (PICU) length of stay (LOS).

Abbreviations: HFOV, high-frequency oscillatory ventilation; CMV, conventional mechanical ventilation.

0.004 for the first 24 hours, 48 hours, 72 hours and the last day, respectively). OI and $\mathrm{PaCO}_{2}$ tended to decrease during the first three study days and on the last day their values improved significantly ( $P=0.001$ and 0.031 , respectively).
Given that the median $\mathrm{pH}$ at each time point was within normal range, the change of $\mathrm{pH}$ made little sense in the present study (Table 3).

\section{Variables associated with mortality}

Fourteen of the 48 patients died: 9 of 26 (34.62\%) patients utilizing HFOV and 5 of $22(22.73 \%)$ patients receiving $\mathrm{CMV}$ alone. Analysis demonstrated that survivors were younger $(P=0.025)$, lighter $(P=0.025)$, had a better PRISM III score $(P=0.021)$, lower PEEP $(P=0.027)$ and PIP $(P=0.047)$ in the setting of $\mathrm{CMV}$ prior to HFOV than nonsurvivors undergoing HFOV (Table 4). In the CMV group, patients who were immunocompromised were less likely to survive than those who were not ( $100.0 \%$ vs $29.41 \%, P=0.010)$. In the mortality analysis, the hazard ratio for weight was 1.198 (per every one unit increase, $P=0.020,95 \%$ CI 1.029 to 1.396 ) and the presence of multiple organ dysfunction syndrome (MODS) was 17.796 ( $P=0.006,95 \%$ CI 2.246 to 141.022$)$ in the HFOV group (Table 5). Despite the extremely high hazard ratio, the presence of immunocompromised state was neither a risk nor a protective factor for survival in patients receiving CMV ( $P=0.354,95 \%$ CI 0.011 to $269,603.047$ ).
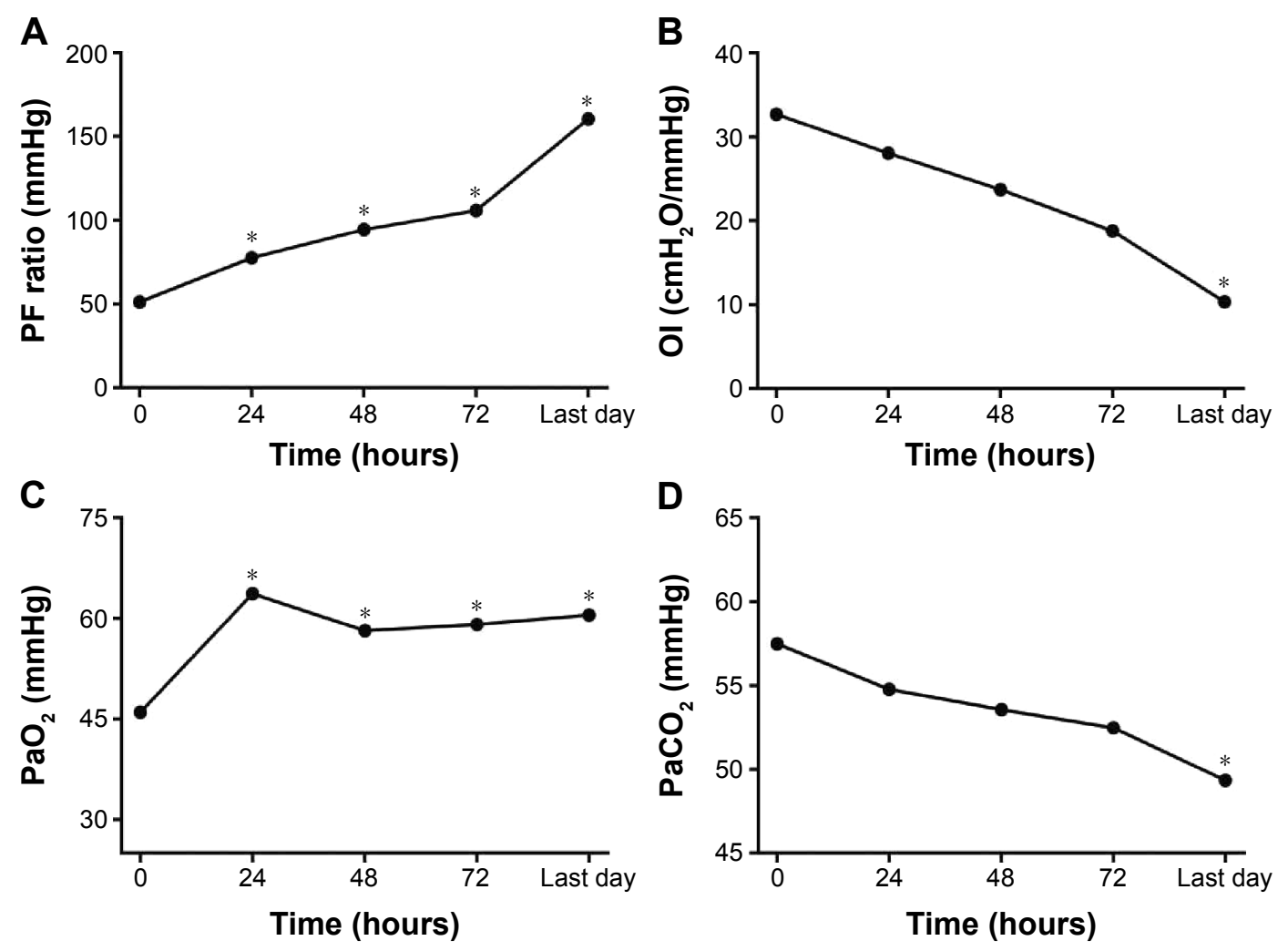

Figure 3 Blood gas analyses during high-frequency oscillatory ventilation (HFOV).

Notes: Change of PF ratio (A), OI (B), $\mathrm{PaO}_{2}(\mathbf{C})$ and $\mathrm{PaCO}_{2}$ (D) during the first 72 hours and the last day of HFOV. The parameters at 0 hour are the parameters immediately preceding HFOV and set as reference. Values of each parameter were presented as median. *Means significant change $(P<0.05)$ when compared with parameters at 0 hour by generalized estimating equation analysis.

Abbreviations: $\mathrm{PF}$ ratio, $\mathrm{PaO}_{2} / \mathrm{FiO}_{2}$ ratio; $\mathrm{PaO}_{2}$, arterial partial pressure of oxygen; $\mathrm{FiO}_{2}$, fraction of inspired oxygen; OI, oxygenation index; PaCO , partial pressure of carbon dioxide. 
Table 3 Blood gas analyses during high-frequency oscillatory ventilation (HFOV)

\begin{tabular}{|c|c|c|c|c|c|c|c|c|c|}
\hline Parameters & $\begin{array}{l}\text { Immediately } \\
\text { preceding HFOV }\end{array}$ & 24 hours & $P$-value ${ }^{a}$ & 48 hours & $P$-value ${ }^{a}$ & 72 hours & $P$-value ${ }^{a}$ & Last day & $P$-value ${ }^{a}$ \\
\hline $\mathrm{OI}\left(\mathrm{cmH}_{2} \mathrm{O} / \mathrm{mmHg}\right)$ & $32.67(24.85)$ & $28.04(24.86)$ & 0.608 & $23.72(24.23)$ & 0.739 & $18.80(21.76)$ & 0.477 & $10.36(40.21)$ & 0.001 \\
\hline $\mathrm{PaO}_{2} / \mathrm{FiO}_{2}(\mathrm{mmHg})$ & $46.60(41.96)$ & $77.54(25.77)$ & 0.005 & $94.99(61.61)$ & 0.008 & $108.08(63.92)$ & 0.003 & $171.10(197.01)$ & $<0.001$ \\
\hline $\mathrm{PaO}_{2}(\mathrm{mmHg})$ & $47.50(26.75)$ & $64.50(13.10)$ & 0.013 & $58.85(24.94)$ & 0.090 & $59.10(33.90)$ & 0.008 & $67.34(30.90)$ & 0.004 \\
\hline $\mathrm{pH}$ & $7.39(0.16)$ & $7.40(0.21)$ & 0.705 & $7.43(0.14)$ & 0.203 & $7.43(0.11)$ & 0.029 & $7.44(0.17)$ & 0.215 \\
\hline $\mathrm{PaCO}_{2}(\mathrm{mmHg})$ & $54.00(31.50)$ & $55.10(18.45)$ & 0.483 & $52.20(16.12)$ & 0.242 & $49.85(17.27)$ & 0.196 & 40.71 (22.58) & 0.031 \\
\hline
\end{tabular}

Notes: Data were presented by median (interquartile range). ${ }^{2}$ Data at the first 24 hours, 48 hours, 72 hours and the last day after commencing HFOV compared with data immediately preceding HFOV using the generalized estimating equation analysis; $P$-value $>0.05$ is considered significant.

Abbreviations: $\mathrm{Ol}$, oxygenation index; $\mathrm{PaO}_{2}$, arterial partial pressure of oxygen; $\mathrm{FiO}_{2}$, fraction of inspired oxygen; $\mathrm{pH}$, potential of hydrogen; $\mathrm{PaCO}$, partial pressure of carbon dioxide.

\section{Discussion}

In this study, we found that in severe PARDS patients with hypoxemia refractory to CMV, HFOV as an alternative approach could improve oxygenation efficiently. We also observed a decreasing trend in $\mathrm{PaCO}_{2}$ during the first 72 hours. This result, despite having no statistical significance, suggested that HFOV did not raise the incidence of hypercapnia. The mechanism was that the speedy motion of gas molecules and high flow during HFOV could facilitate extended oxygen mixing and exchange, as well as promote $\mathrm{PaCO}_{2}$ clearance in theory. ${ }^{6}$ Although Derdak et al showed that $\mathrm{HFOV}$ slightly increased $\mathrm{PaCO}_{2}$ in adults, ${ }^{15}$ a recent study demonstrated that $\mathrm{HFOV}$ reduced $\mathrm{PaCO}_{2}$ efficiently in ARDS of pulmonary origin with hypercapnic failure of

Table 4 Univariate test of characteristics associated with mortality

\begin{tabular}{|c|c|c|c|c|c|c|}
\hline \multirow[t]{2}{*}{ Variable } & \multicolumn{2}{|l|}{ HFOV } & \multirow[t]{2}{*}{$P$-value } & \multicolumn{2}{|l|}{ CMV } & \multirow[t]{2}{*}{$P$-value } \\
\hline & $\begin{array}{l}\text { Survived } \\
(n=17)\end{array}$ & $\begin{array}{l}\text { Non-survived } \\
(n=9)\end{array}$ & & $\begin{array}{l}\text { Survived } \\
(n=17)\end{array}$ & $\begin{array}{l}\text { Non-survived } \\
(n=5)\end{array}$ & \\
\hline Age/mo & $7.00(10.50)$ & $25.00(67.00)$ & 0.025 & $4 I .00(48.50)$ & $32.00(88.50)$ & 0.704 \\
\hline Male & $10(58.82 \%)$ & $3(33.33 \%)$ & $0.41 \mathrm{I}$ & $10(58.82 \%)$ & $2(40.00 \%)$ & 1.000 \\
\hline Weight/kg & $6.00(3.50)$ & $12.00(10.55)$ & 0.025 & I5.50 (9.50) & II .50 (22.20) & 0.940 \\
\hline PRISM III score & $6.00(8.00)$ & $13.00(5.00)$ & 0.021 & $6.82 \pm 3.54$ & $5.80 \pm 4.87$ & 0.606 \\
\hline \multicolumn{7}{|l|}{ Diagnosis } \\
\hline Pneumonia & $16(94.12 \%)$ & 7 (77.78\%) & 0.268 & $12(70.57 \%)$ & $4(80.00 \%)$ & 1.000 \\
\hline Congenital heart disease & $7(41.18 \%)$ & $3(33.33 \%)$ & 1.000 & $2(\mathrm{II} .76 \%)$ & I (20.00\%) & 1.000 \\
\hline Immunocompromised & $3(17.65 \%)$ & 4 (44.44\%) & 0.188 & $5(29.41 \%)$ & $5(100.0 \%)$ & 0.010 \\
\hline Sepsis & $2(11.76 \%)$ & $3(33.33 \%)$ & 0.302 & $7(41.18 \%)$ & $2(40.00 \%)$ & 1.000 \\
\hline CNS disease & $2(11.76 \%)$ & $3(33.33 \%)$ & 0.302 & $5(29.41 \%)$ & I (20.00\%) & 1.000 \\
\hline MODS & I (5.88\%) & $3(33.33 \%)$ & 0.104 & $5(29.41 \%)$ & $0(0.00 \%)$ & 0.290 \\
\hline Air leak & $2(11.76 \%)$ & $2(22.22 \%)$ & 0.591 & I (5.88\%) & I (20.00\%) & 0.411 \\
\hline Vasoactive agents usage & $16(94.12 \%)$ & $9(100 \%)$ & 1.000 & $10(58.82 \%)$ & $4(80.00 \%)$ & 0.613 \\
\hline PICU LOS/hour & $631.06 \pm 376.59$ & $430.56 \pm 336.599$ & 0.194 & $264.00(192.00)$ & $408.00(744.00)$ & 0.820 \\
\hline Ventilatory duration/hour & $496.94 \pm 291.57$ & $432.44 \pm 342.20$ & 0.618 & $147.24 \pm 69.16$ & $254.80 \pm 242.25$ & 0.380 \\
\hline \multicolumn{7}{|l|}{ Ventilation setting at 0 hour $^{\mathrm{a}}$} \\
\hline $\mathrm{PEEP} / \mathrm{cmH}_{2} \mathrm{O}$ & $7.00(2.75)$ & $10.00(6.00)$ & 0.027 & $7.00(2.50)$ & $7.00(7.00)$ & 0.649 \\
\hline $\mathrm{PIP} / \mathrm{cmH}_{2} \mathrm{O}$ & $27.50 \pm 3.81$ & $30.96 \pm 4.21$ & 0.047 & $25.00(7.50)$ & $26.00(13.00)$ & 0.595 \\
\hline $\mathrm{MAP} / \mathrm{cmH}_{2} \mathrm{O}$ & $15.59 \pm 2.80$ & $18.22 \pm 3.72$ & 0.151 & $14.80(3.10)$ & $13.40(8.20)$ & 0.880 \\
\hline $\mathrm{RR} /$ per min & $35(7.67)$ & $30(6.00)$ & 0.301 & $30(0.00)$ & $30(7.00)$ & 0.543 \\
\hline \multicolumn{7}{|l|}{ Blood gas analyses at 0 hour ${ }^{a}$} \\
\hline $\mathrm{PF} / \mathrm{mmHg}$ & $51.19(27.24)$ & $61.75(48.62)$ & 0.945 & $67.50(81.38)$ & $60.00(55.66)$ & 0.497 \\
\hline $\mathrm{Ol} / \mathrm{cmH}_{2} \mathrm{O} \cdot \mathrm{mmHg}^{-1}$ & $30.37 \pm 12.18$ & $36.51 \pm 18.30$ & 0.744 & $21.59(19.40)$ & $24.33(68.25)$ & 0.612 \\
\hline $\mathrm{PaO}_{2} / \mathrm{mmHg}$ & $46.00(21.75)$ & $53.50(31.50)$ & 0.677 & $58.49 \pm 26.03$ & $45.40 \pm 17.42$ & 0.388 \\
\hline $\mathrm{PaCO}_{2} / \mathrm{mmHg}$ & $52.50(26.25)$ & $46.00(37.50)$ & 0.447 & $40.21 \pm 10.13$ & $39.00 \pm 8.77$ & 0.688 \\
\hline $\mathrm{pH}$ & $7.45(0.12)$ & $7.32(0.10)$ & 0.079 & $7.40(0.11)$ & $7.39(0.12)$ & 1.000 \\
\hline
\end{tabular}

Notes: Data were presented by median (interquartile range), mean \pm SD or numbers (percentage). Continued variables were compared using Mann-Whitney $U$-test or independent $t$-test and categorical variables using Fisher's exact or Pearson's chi-square test; $P$-value $>0.05$ is considered significant. 0 hour means immediately preceding HFOV in the HFOV group and the initiation of CMV in the CMV group.

Abbreviations: HFOV, high-frequency oscillatory ventilation; CMV, conventional mechanical ventilation; PRISM III score, Pediatric Risk of Mortality III score; PICU LOS, pediatric intensive care unit length of stay; CNS, central nervous system; MODS, multiple organ dysfunction syndrome; PEEP, positive end expiratory pressure; PIP, peak inspiratory pressure; MAP, mean airway pressure; $\mathrm{RR}$, respiratory rate; $\mathrm{PF}$ ratio, $\mathrm{PaO}_{2} / \mathrm{FiO}_{2}$ ratio; $\mathrm{PaO}_{2}$, arterial partial pressure of oxygen; FiO , fraction of inspired oxygen; $\mathrm{Ol}$, oxygenation index; $\mathrm{PaCO}_{2}$, partial pressure of carbon dioxide; $\mathrm{pH}$, potential of hydrogen; $\mathrm{SD}$, standard deviation. 
Table 5 Summary of Cox proportional hazard model for mortality

\begin{tabular}{llll}
\hline Variables & $\begin{array}{l}\text { Hazard ratio } \\
\text { for nonsurvival }\end{array}$ & $\begin{array}{l}\mathbf{9 5 \%} \text { confidence } \\
\text { interval }\end{array}$ & P-value \\
\hline $\begin{array}{l}\text { HFOV group } \\
\text { Weight (per every } \\
\text { one unit increase) }\end{array}$ & 1.198 & $(1.029-1.396)$ & 0.020 \\
$\begin{array}{l}\text { Presence of MODS } \\
\text { CMV group }\end{array}$ & 17.796 & $(2.246-141.022)$ & 0.006 \\
$\begin{array}{l}\text { Presence of } \\
\text { immunocompromised }\end{array}$ & 55.382 & $(0.011-269$, & 0.354 \\
\hline
\end{tabular}

Notes: Cox proportional hazard model was used to determine the risk factor related to mortality in HFOV and CMV groups, respectively; $P$-value $>0.05$ is considered significant.

Abbreviations: HFOV, high-frequency oscillatory ventilation; MODS, multiple organ dysfunction syndrome; CMV, conventional mechanical ventilation.

CMV.${ }^{16}$ Hence, the unremarkable effect on $\mathrm{CO}_{2}$ removal in our study may be due to the heterogeneous etiology and small sample population.

The mortality of patients with severe PARDS, based on the 2015 PARDS diagnostic criteria, was high at $\sim 30 \%-45 \%{ }^{17}$ Since HFOV did not improve the outcomes, including reduced standardized mortality, this ventilation approach was not recommended as the routine or for early application both in pediatrics and adults with ARDS. ${ }^{11,18}$ However, the overall in-hospital mortality in the present study was $29.17 \%$ (34.62\% in the HFOV group and $22.73 \%$ in the CMV group). The results from our study indicated that the application of HFOV did not increase the in-hospital mortality in children with severe PARDS. In fact, the children in the HFOV group were sicker than the CMV children, and the study did not involve the evaluation of oxygenation improvement during ventilation treatment in the previous study. ${ }^{11}$ In the real world clinical practice, HFOV was usually conducted as an alternative approach in severe PARDS patients with hypoxemia refractory to CMV. Given that continued hypoxemia is associated with worse outcomes, ${ }^{2,17}$ we emphasized its rescue role in PARDS with oxygenation failure on CMV, and our study showed that HFOV may alleviate worsening hypoxemia in these patients.

Although the PRISM III scores and presence of coexisting conditions were similar between the two ventilation groups, patients who required transition to HFOV received higher ventilation setting during CMV. They had a higher frequency of the usage of vasoactive agents, longer PICU stay and mechanical ventilation duration in comparison with those in the CMV group. Since there is no strong evidence to suggest that HFOV has a hemodynamic effect on patients with PARDS, an increased use of vasoactive agents implies that children in the HFOV group were worse off clinically.
This may also explain why pediatric patients receiving HFOV had a longer PICU stay and ventilation duration. Given the effect of HFOV on oxygenation improvement and $\mathrm{CO}_{2}$ clearance, we confirmed that HFOV could be a rescue therapy or alternative approach in patients with severe PARDS refractory to CMV.

PARDS is a heterogeneous disease induced by variable causes and is accompanied with a variety of clinical conditions. Thus, another objective in this study was to identify risk factors associated with outcomes in PARDS patients. Several groups have reported that immunocompromised condition markedly increased mortality in ARDS patients undergoing HFOV. ${ }^{19,20}$ Other published physiological predictors of survival during HFOV included an OI of less than 35 , improvement in the $\mathrm{PaO}_{2} / \mathrm{FiO}_{2}$ ratio of more than $38 \%$ within 72 hours after commencement of HFOV, the ratio of OI preceding HFOV to the OI after 24 hours $\left(\mathrm{OI}_{24 \mathrm{~h} / \mathrm{pre}}\right)$ of more than 1 and so on. ${ }^{19-21}$ These data indicated that the degree of hypoxemia, oxygenation reaction to HFOV and underlying conditions might contribute to the outcomes of patients undergoing HFOV. Interestingly, our data showed that the incidence of MODS was passively correlated with in-hospital mortality in children receiving HFOV. It was conceivable that, despite similarity in the severity of illness scores between the two groups, the children in the HFOV group were sicker than those in the CMV group.

The influence of age and weight on the mortality of pediatric patients with ARDS undergoing HFOV remains controversial. In our study, we observed a positive correlation between body weight and mortality in patients receiving HFOV. Some groups have also reported that low weight or younger patients with acute respiratory failure benefited more from HFOV. ${ }^{21,22}$ In contrast, a meta-analysis revealed that elective HFOV had no beneficial effect over CMV in preterm infants based on the gestational age and birth weight. ${ }^{23}$ One possible explanation is that younger or lower weight patients have better lung compliance. Alternatively, the differences in outcomes could be due to a variety of HFOV protocols employed.

Ventilator-induced lung injury is a common complication of ARDS, especially in patients with severe hypoxemia. This is because these patients often have worse lung compliance and require relatively large tidal volumes or high airway pressure. Our group implemented a lung-protective strategy of volume and pressure limitation during CMV, which could reduce the incidence of pneumothorax or mortality as demonstrated by several studies. ${ }^{24,25}$ In this study, we found no difference in the incidence of new air leaks between the two 
ventilation groups. These results implied that HFOV could be safely utilized.

The main limitation of this study is the small sample size, which may have lowered the credibility of our results. Additionally, this study is a retrospective and observational review, so it is difficult to compare the changes in oxygenation between the two groups. Therefore, further research is required, particularly a prospective study with a larger sample of patients.

\section{Conclusion}

We presented our experience with regard to HFOV practices and found that HFOV was an efficient alternative therapy that could significantly improve hypoxemia and promote $\mathrm{CO}_{2}$ removal in patients with oxygenation deterioration on CMV. The mortality was associated with the presence of MODS and heavier body weight in the HFOV group.

\section{Acknowledgments}

This study was supported by the National Natural Science Foundation of China (Grant no 81470219) and Science and Technology Projects Foundation of Guangdong Province (Grant no 2014A020212120). We appreciate professor PeiYing Feng for proofing our manuscript.

\section{Author contributions}

Yu-Xiong Guo and Zhao-Ni Wang designed the study and participated in the drafting of manuscript. Ya-Ting Li, Li-Pan and Li-Fen Yang participated in the data collection and revisions of the draft. Yan-Hu, Yue-Yu Sun and LiangMing Cai participated in the data collection and manuscript interpretation. Zhuang-Gui Chen designed the study, drafted the manuscript and participated in the critical revisions of the draft. All authors contributed toward data analysis, drafting and critically revising the paper and agree to be accountable for all aspects of the work.

\section{Disclosure}

The authors report no conflicts of interest in this work.

\section{References}

1. Quasney MW, López-Fernández YM, Santschi M, Watson RS; Pediatric Acute Lung Injury Consensus Conference Group. The outcomes of children with pediatric acute respiratory distress syndrome: proceedings from the Pediatric Acute Lung Injury Consensus Conference. Pediatr Crit Care Med. 2015;16(5 Suppl 1):S118-S131.

2. ARDS Definition Task Force, Ranieri VM, Rubenfeld GD, et al. Acute respiratory distress syndrome: the Berlin definition. JAMA. 2012;307(23): 2526-2533.

3. Kuchnicka K, Maciejewski D. Ventilator-associated lung injury. Anaesthesiol Intensive Ther. 2013;45(3):164-170.
4. Imai Y, Slutsky AS. High-frequency oscillatory ventilation and ventilatorinduced lung injury. Crit Care Med. 2005;33(3 Suppl):S129-S134.

5. Facchin F, Fan E. Airway pressure release ventilation and high-frequency oscillatory ventilation: potential strategies to treat severe hypoxemia and prevent ventilator-induced lung injury. Respir Care. 2015;60(10): $1509-1521$.

6. Slutsky AS, Drazen JM. Ventilation with small tidal volumes. N Engl J Med. 2002;347:630-631.

7. Moniz M, Silvestre C, Nunes $P$, et al. High-frequency oscillatory ventilation in children: a 10-year experience. J Pediatr (Rio J). 2013;89(1): $48-55$.

8. Babbitt CJ, Cooper MC, Nussbaum E, Liao E, Levine GK, Randhawa IS. High-frequency oscillatory ventilation in pediatric acute hypoxemic respiratory failure: disease-specific morbidity survival analysis. Lung. 2012;190(6):685-690.

9. Pediatric Acute Lung Injury Consensus Conference Group. Pediatric acute respiratory distress syndrome: consensus recommendations from the pediatric acute lung injury consensus conference. Pediatr Crit Care Med. 2015;16(5):428-439.

10. Lall R, Hamilton P, Young D, et al. A randomised controlled trial and cost-effectiveness analysis of high-frequency oscillatory ventilation against conventional artificial ventilation for adults with acute respiratory distress syndrome. The OSCAR (OSCillation in ARDS) study. Health Technol Assess. 2015;19(23):1-177.

11. Gupta P, Green JW, Tang X. Comparison of high-frequency oscillatory ventilation and conventional mechanical ventilation in pediatric respiratory failure. JAMA Pediatr. 2014;168(3):243-249.

12. McIntyre RC, Pulido EJ, Bensard DD, Shames BD, Abraham E. Thirty years of clinical trials in acute respiratory distress syndrome. Crit Care Med. 2000;28(9):3314-3331.

13. Hager DN, Krishnan JA, Hayden DL, Brower RG. ARDS Clinical Trials Network. Tidal volume reduction in patients with acute lung injury when plateau pressures are not high. Am J Respir Crit Care Med. 2005; 172(10):1241-1245.

14. Esan A, Hess DR, Raoof S, George L, Sessler CN. Severe hypoxemic respiratory failure: part 1 - ventilatory strategies. Chest. 2010;137(5): 1203-1216.

15. Derdak S, Mehta S, Stewart TE, et al; Multicenter Oscillatory Ventilation For Acute Respiratory Distress Syndrome Trial (MOAT) Study Investigators. High-frequency oscillatory ventilation for acute respiratory distress syndrome in adults: a randomized, controlled trial. Am J Respir Crit Care Med. 2002;166(6):801-808.

16. Friesecke S, Stecher SS, Abel P. High-frequency oscillation ventilation for hypercapnic failure of conventional ventilation in pulmonary acute respiratory distress syndrome. Crit Care. 2015;19:201.

17. Khemani RG, Smith LS, Zimmerman JJ, Erickson S; Pediatric Acute Lung Injury Consensus Conference Group. Pediatric acute respiratory distress syndrome: definition, incidence, and epidemiology: proceedings from the Pediatric Acute Lung Injury Consensus Conference. Pediatr Crit Care Med. 2015;16(5 Suppl 1):S23-S40.

18. Ferguson ND, Cook DJ, Guyatt GH, et al. High-frequency oscillation in early acute respiratory distress syndrome. $N$ Engl J Med. 2013;368(9): $795-805$.

19. Rettig JS, Smallwood CD, Walsh BK, et al. High-frequency oscillatory ventilation in pediatric acute lung injury: a multicenter international experience. Crit Care Med. 2015;43(12):2660-2667.

20. Yehya N, Topjian AA, Lin R, Berg RA, Thomas NJ, Friess SH. High frequency oscillation and airway pressure release ventilation in pediatric respiratory failure. Pediatr Pulmonol. 2014;49(7):707-715.

21. Camporota L, Sherry T, Smith J, Lei K, McLuckie A, Beale R. Physiological predictors of survival during high-frequency oscillatory ventilation in adults with acute respiratory distress syndrome. Crit Care. 2013; 17(2):R40.

22. Courtney SE, Durand DJ, Asselin JM, Hudak ML, Aschner JL, Shoemaker CT; Neonatal Ventilation Study Group. High-frequency oscillatory ventilation versus conventional mechanical ventilation for very-low-birth-weight infants. $N$ Engl J Med. 2002;347(9):643-652. 
23. Cools F, Askie LM, Offringa M, et al. Elective high-frequency oscillatory versus conventional ventilation in preterm infants: a systematic review and meta-analysis of individual patients' data. Lancet. 2010;375(9731): 2082-2091.

24. Miller MP, Sagy M. Pressure characteristics of mechanical ventilation and incidence of pneumothorax before and after the implementation of protective lung strategies in the management of pediatric patients with severe ARDS. Chest. 2008;134(5):969-973.
25. The Acute Respiratory Distress Syndrome Network. Ventilation with lower tidal volumes as compared with traditional tidal volumes for acute lung injury and the acute respiratory distress syndrome. $N$ Engl J Med. 2000;342:1301-1308.

Therapeutics and Clinical Risk Management

\section{Publish your work in this journal}

Therapeutics and Clinical Risk Management is an international, peerreviewed journal of clinical therapeutics and risk management, focusing on concise rapid reporting of clinical studies in all therapeutic areas outcomes, safety, and programs for the effective, safe, and sustained use of medicines. This journal is indexed on PubMed Central, CAS,
EMBase, Scopus and the Elsevier Bibliographic databases. The manuscript management system is completely online and includes a very quick and fair peer-review system, which is all easy to use. Visit http://www.dovepress.com/testimonials.php to read real quotes from published authors.

Submit your manuscript here: http://www.dovepress.com/therapeutics-and-clinical-risk-management-journal 